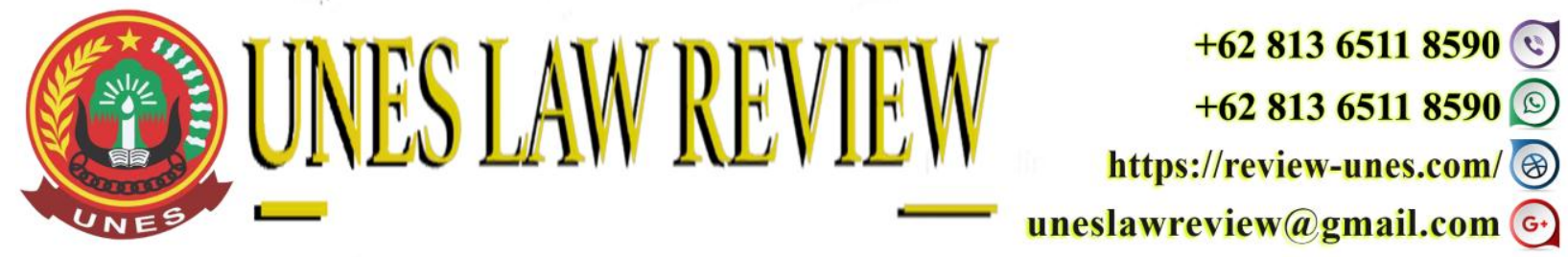

DOI: https://doi.org/10.31933/unesrev.v4i1

Diterima: 24/09/2021, Diperbaiki: 07/10/2021, Diterbitkan: 20/10/2021

\title{
KOORDINASI ANTARA MUSYAWARAH NAGARI (MUSRI) DENGAN BHABINKAMTIBMAS POLRES SAWAHLUNTO DALAM PENANGGULANGAN KEJAHATAN DI KOTA SAWAHLUNTO
}

\section{Asri Joni}

Program Magister Ilmu Hukum, Universitas Ekasakti, Padang, Indonesia.

Email: asrijoni1@gmail.com

Corresponding Author: Asri Joni

\section{ABSTRACT}

The coordination between the nagari deliberation (Musri) in Sawahlunto City and the Bhabinkamtibmas of the Sawahlunto Police in dealing with crime is through unification activities carried out by Bhabinkamtibmas on the activities of the elements in Musri. Coordination is carried out to create a sense of security for the entire community, especially to anticipate crimes such as theft that often occur in Sawahlunto City. This coordination can also encourage people to exchange ideas. The existence of coordination between the Nagari Deliberation and Bhabinkamtibmas in Sawahlunto City which is carried out in each village makes it easier to control criminal acts in each region, as well as in conducting socialization, by inviting village heads and the community to submit and request information and input from the village community in Sawahlunto City. Obstacles in Empowering Nagari Deliberation Cooperation (Musri) in Sawahlunto City with Bhabinkamtibmas Sawahlunto Police in Crime Prevention include the presence of a third party who interferes in a problem, affecting the problem solving process carried out by Bhabinkamtibmas. Lack of understanding of the community towards the laws and regulations that apply so that many people who stumble into problems want to win on their own without thinking about other parties. Some of the Bhabinkamtibmas officers did not fully understand the problem-solving techniques they faced.

Keywords: Coordination, Musri, Bhabinkamtibmas, Crime

\section{ABSTRAK}

Koordinasi antara musyawarah nagari (Musri) di Kota Sawahlunto dengan Bhabinkamtibmas Polres Sawahlunto dalam penanggulangan kejahatan adalah dengan kegiatan-kegiatan penyatuan yang dilakukan oleh Bhabinkamtibmas terhadap kegiatan unsur unsur yang ada di dalam Musri. Koordinasi dilakukan untuk menciptakan rasa aman bagi seluruh masyarakat, khususnya untuk mengantisipasi agar tindak kejahatan seperti pencurian yang sering terjadi di Kota Sawahlunto. Koordinasi ini juga dapat mendorong masyarakat untuk bertukar pikiran. Terdapatnya koordinasi 
antara Musyawarah nagari dengan Bhabinkamtibmas di Kota Sawahlunto yang dilakukan di setiap Desa memudahkan untuk mengontrol tindakan-tindakan kejahatan di setiap wilayah, juga dalam melakukan sosialisasi, dengan mengundang kepala desa serta masyarakat guna menyampaikan dan meminta informasi-informasi dan masukan dari masyarakat Desa di Kota Sawahlunto. Kendala Dalam Pemberdayaan Kerjasama Musyawarah Nagari (Musri) Di Kota Sawahlunto Dengan Bhabinkamtibmas Polres Sawahlunto Dalam Penanggulangan Kejahatan diantaranya adanya pihak ketiga yang ikut campur dalam sebuah permasalahan, mempengaruhi proses penyelesaian masalah yang dilakukan oleh Bhabinkamtibmas. Kurang mengertinya masyarakat terhadap hukum dan aturan aturan yang berlaku sehingga banyak masyarakat yang tersandung masalah ingin menang sendiri tanpa memikirkan pihak lain. Beberapa petugas Bhabinkamtibmas yang belum memahami secara keseluruhan tentang teknik penyelesaian masalah yang dihadapinya.

Kata Kunci: Koordinasi, Musri, Bhabinkamtibmas, Kejahatan

\section{PENDAHULUAN}

Negara modern dimanapun di dunia menjunjung supremasi hukum. Masing-masing negara mempunyai sistem peradilan pidana yang khas karena memiliki latar belakang sejarah dan perkembangan masyarakat yang berbeda, tetapi dengan perkembangan dan kemajuan teknologi membuat batas-batas Negara menjadi tanpa batas mengarah pada persamaan dan menghilangkan perbedaan. Sistem hukum suatu negara akan terbentuk dari pertumbuhan tata nilai hukum yang berlaku dalam masyarakat dan organisasi alat perlengkapan Negara penegak hukum negara itu sendiri. Pandangan sejarah, sosial ekonomi, filsafat, dan politik bangsa merupakan sumber yang menentukan terbentuknya pola sistem hokum (Bambang Poernomo, 1993:70).

Kejahatan atau kriminalitas (crime) telah menjadi bagian yang inherent dalam sejarah kehidupan umat manusia sejak jaman dahulu hingga saat ini. Menurut sosiolog Emille Durkheim, kejahatan itu normal ada di semua masyarakat dan hampir tidak mungkin menghilangkan kejahatan dalam masyarakat (Zainuddin Ali, 2009:52). Kejahatan memiliki fungsi dan disfungsi dalam masyarakat. Kejahatan bersifat disfungsi karena memberikan efek yang merusak terhadap tatanan sosial, menimbulkan rasa tidak aman dan ketakutan serta menambah beban ekonomi yang besar bagi masyarakat. Selain bersifat disfungsi, kejahatan juga dapat memberikan efek positif bagi pembangunan fungsi sosial. Kejahatan dapat menumbuhkan rasa solidaritas dalam kelompok, memunculkan norma-norma atau aturan yang mampu mengatur masyarakat serta mampu memperkuat penegakkan hukum, serta menambah kekuatan fisik atau organisasi untuk memberantas kejahatan.

Menurut Robert L. O’Block (1981:1-3) menyatakan bahwa kejahatan adalah masalah sosial, maka usaha pencegahan kejahatan yang merupakan usaha yang melibatkan berbagai pihak. Bahwa konsep pencegahan kejahatan (crime prevention) menurut The National Crime Prevention Institute is defines crime prevention as the anticipation, recognition and appraisal of a crime risk and the initiation of some action to remove or reduce it. Definisi pencegahan kejahatan adalah proses antisipasi, identifikasi dan estimasi resiko akan terjadinya kejahatan dan melakukan inisiasi atau sejumlah tindakan untuk menghilangkan atau mengurangi kejahatan. 
Sedangkan menurut Venstermark dan Blauvelt mempunyai definisi lain tentang konsep pencegahan kejahatan yaitu crime prevention means, practically reducing the probality criminalactivity, yang artinya pencegahan kejahatan berarti mengurangi kemungkinan atas terjadinya aksi kejahatan (Robert J. Fischer and Gion Green, 1998:144). Kemudian Fisher juga mengemukan pendapatnya yaitu to determind the amount of force a security officer may use to prevent crime, the court have consider circumstances, the seriousness of the crime prevented and the possibility of preventing the crime by other means. (Untuk menentukan jumlah kekuatan petugas pengamanan yang dapat digunakan untuk mencegah kejahatan, pengelola mempertimbangkan keadaan, keseriusan mencegah kejahatan dan kemungkinan mencegah kejahatan dengan cara lain).

Masih terbatasnya kasus-kasus kejahatan yang belum berhasil diungkap polisi (clearence rate) ditambah banyaknya kasus kejahatan yang tidak dilaporkan ke polisi serta perkembangan ragam, bentuk dan modus kejahatan dewasa ini, membuat tugas-tugas kepolisian terasa semakin berat tantangannya. Polri berusaha mengubah strategi penanganan kejahatan dari pendekatan yang cenderung bersifat represif (penindakan), menjadi penanganan kejahatan yang lebih memprioritaskan pada pendekatan pre-emtif dan preventif (pencegahan). Dengan perubahan strategi tersebut, diharapkan Polri mampu menekan tingkat kejahatan secara bertahap sehingga mampu menciptakan situasi kamtibmas yang kondusif untuk mendukung keamanan daerah.

Situasi kamtibmas sangat diharapkan oleh seluruh masyarakat untuk dapat diwujudkan, sehingga menimbulkan perasaan tentram dan damai bagi setiap masyarakat dan dapat meningkatkan motivasi dan semangat dalam bekerja, karena tidak ada rasa takut akibat kemungkinan adanya gangguan yang akan menimpa. Polri memiliki tugas yang cukup berat dalam pencegahan terjadinya pelanggaran dan kejahatan, pelayanan masyarakat dan melindungi serta menertibkan masyarakat (Sadjijono, 2010:12).

Polisi sendiri dalam hal ini sudah mempersiapkan personil yang mewakili bidang pembinaan masyarakat. Intinya membangun kemitraan antara Polri dengan masyarakat sehingga terwujud rasa saling percaya, saling menghargai dan saling menghormati antara Polri dengan masyarakat (Satjipto Raharjo, 2003:11). Sehingga Polri dapat diterima dan didukung oleh masyarakat. Kegiatan Polri untuk mendorong, mengarahkan, dan menggerakkan masyarakat untuk berperan dalam Binkamtibmas (Pembina Keamanan dan Ketertiban Masyarakat) melalui bentuk Pamswakarsa dan penerapan model perpolisian masyarakat (Community Policing) antara lain dilakukan melalui penugasan anggota Polri menjadi Bhayangkara Pembina Kamtibmas yang selanjutnya disebut Bhabinkamtibmas selaku dasar acuan adalah Surat Kepala Kepolisian Negara Republik Indonesia Nomor: B/3377/IX/2011/Baharkam tanggal 29 September 2011 tentang Penggelaran Bhabinkamtibmas di Desa/Kelurahan. Bhayangkara Pembina Keamanan dan Ketertiban Masyarakat (BHABINKAMTIBMAS) adalah anggota Kepolisian Negara Republik Indonesia (POLRI) yang bertugas membina keamanan dan ketertiban masyarakat (kamtibmas) (Buku Pintar BHABINKAMTIBMAS, 2014:3).

Mengembangkan potensi dan kekuatan masyarakat dalam menanggulangi tindak pidana dapat dilakukan dengan memberdayakan lembaga lembaga yang ada dalam masyarakat baik itu 
lembaga adat ataupun lembaga nagari. Dikota Sawahlunto terdapat lembaga Musyawarah nagari (Musri) yang berkedudukan pada setiap nagari. Melalui lembaga Musri ini dilakukan kerjasama dengan Bhabinkamtibmas dalam upaya penanggulangan kejahatan.

Permasalahan yang akan dibahas adalah koordinasi antara Musyawarah nagari (Musri) Di Kota Sawahlunto dengan Bhabinkamtibmas Polres Sawahlunto dalam penanggulangan Kejahatan serta kendalanya.

\section{METODE PENELITIAN}

Spesifikasi penelitian adalah deskriptif analitis, dengan metode pendekatan yuridis normative didukung oleh yuridis empiris. Jenis data yang digunakan adalah data sekunder dan data primer. Data sekunder diperoleh dari studi dokumen, data primer diperoleh dengan cara wawancara. Data yang diperoleh kemudian dianalisa secara kualitatif .

\section{HASIL DAN PEMBAHASAN}

\section{Koordinasi Antara Musyawarah Nagari (Musri) Di Kota Sawahlunto Dengan} Bhabinkamtibmas Polres Sawahlunto Dalam Penanggulangan Kejahatan

Kegiatan sehari hari yang dilakukan oleh Bhabinkamtibmas adalah sambang atau melakukan kunjungan kerumah rumah warga masyarakat. Tugas Bhabinkamtibmas yang terlihat sederhana namun sungguh mulia. Bhabinkamtibmas harus mampu memfasilitasi permasalahan agar diselesaikan melalui Forum yang lebih tetap baik melalui Musyawarah Nagari (Musri) yaitu forum kemitraan dengan instansi Pemerintah di tingkat Desa /Kelurahan dan stek holder yang ada dalam masyarakat.

Usaha-usaha Polri dalam menciptakan ketertiban dan keamanan dengan menerapkan konsep yang berpola pada masyarakat dewasa ini dapat dilihat sebagai ujung tombak Polisi karena secara langsung petugas Kepolisian berhubungan dengan warga masyarakat, warga komunitas atau warga kelurahan setempat atau dengan kelompok-kelompok soasial setempat dan dengan umum dimana bertugas.

Bhabinkamtibmas sebagai mediator, atau fasilitator. Dalam penyelesaian masalah dilakukan dengan melibatkan para pihak yang bertikai yakni korban dan pelaku, Petugas Bhabinkamtibmas, babinsa Koramil, perangkat RT/ RW, Tokoh masyarakat dan Tokoh Pemuda serta Musyawarah Nagar (musri). Bhabinkamtibmas lebih mengedepankan fungsi pengayoman, perlindungan, dan pelayanan masyarakat ketimbang fungsi selaku penegak Hukum. Pertiakaian/permasalahan dalam skala ringan diupayakan selesaikan secara kekeluargaan setelah terlebih dahulu menampung aspirasi secara keseluruhan.

Pada kasus diatas, Bhabinkamtibmas Desa Sikalang Kota Sawahlunto melakukan koordinasi dengan pihak musyawarah nagari Sawahlunto dalam menanggulangi kejahatan. Koordinasi pihak kepolisian ini tentunya sangat besar dalam melakukan pemberantasan kejahatan pencurian tersebut, baik pengarahan terhadap masyarakat maupun institusi kepolisian itu sendiri dalam menanggulangi kejahatan pencurian di Desa Sikalang Sawah Lunto. Tidak 
hanya pencurian ringan, tetapi juga pencurian dengan kekerasan dan masih banyak kejahatankejahatan lain yang dilakukan oleh kelompok pencuri. Sehingga, diperlukan adanya kerjasama semua pihak dalam penanggulangannya baik pihak kepolisian, pemerintah setempat, maupun masyarakat.

Koordinasi yang dilakukan oleh Bhabinkamtibmas dengan Musyawarah Nagari (musri) terdiri dari du macam koordinasi yaitu koordinasi vertical dan koordinasi horizontal. Koordinasi Vertikal merupakan kegiatan-kegiatan penyatuan yang dilakukan oleh Bhabinkamtibmas terhadap kegiatan unsur unsur yang ada di dalam Musri. Tegasnya, atasan mengkoordinasi semua aparat yang ada di bawah tanggung jawabnya secara langsung.

Koordinasi vertikal ini secara relatif mudah dilakukan, karena Bhabinkamtibmas dapat melakukan saling introspeksi atau evaluasi kepada unsur unsur lainnya. Koodinasi vertikal juga merupakan kegiatan-kegiatan penyatuan, pengajaran yang dilakukan bhabinkamtibmas Polres Sawahlunto terhadap pemerintah setempat atau Kepala Desa Sikalang beserta masyarakat dalam menanggulangi kejahatan pencurian di Sawahlunto.

Bhabinkamtibmas Desa Sikalang, Kota Sawahlunto menerangkan secara langsung dalam wawancara bahwa Biasanya koordinasi ini dilaksanakan dengan melakukan Kerjasama dengan Musyawarah Nagari (musri), dimana masyarakat dapat memberikan bantuan dengan memberikan informasi-informasi, seperti tempat-tempat yang rawan terjadinya kajahatan, orangorang yang dicurigai melakukan kejahatan, dan lain sebagainya. Sehingga, dengan adanya laporan dari masyarakat, Bhabinkamtibmas akak melaksanakan Razia serta pengejaran terhadap kejahatan misalnya pencurian yang terjadi. Dalam hal ini, peran serta masyarakat dinilai sangat penting dalam mengantisipasi terjadinya pencurian, dengan melibatkan masyarakat, dimana masyarakat dapat memberikan informasi-informasi mengenai setiap sesuatu yang diindikasi sebagai pencurian, dan dengan segera memberikan laporan dan menghubungi bhabinkamtibmas. Hal ini bermaksud agar apabila terjadi suatu tindakan yang dicurigai sebagai tindak pencurian, masyarakat dengan segera menghubungi Bhabinkamtibmas, sehingga Bhabinkamtibmas dapat secepatnya bergerak menuju tempat kejadian perkara untuk melakukan pemeriksaan pada tempat tersebut yang telah dilaporkan masyarakat.

Berdasarkan hasil wawancara di atas, penulis menyimpulkan bahwa dalam menanggulangi kejahatan diantaranya pencurian di Desa Sikalang Sawahlunto, Bhabinkamtibmas Sawahlunto melakukan koordinasi dengan melakukan kerjasama dengan Musri yaitu Forum Kemitraan Polisi Masyarakat, dimana dalam kerjasama tersebut peran serta masyarakat sangat dibutuhkan untuk memberikan informasi tentang titik-titik pencurian yang dicurigai dan meresahkan masyarakat, sehingga dengan adanya informasi terserbut pihak kepolisian dapat secepatnya bergerak ke tempat yang dimaksud untuk melakukan razia atau penggrebekan.

Koordinasi yang dilakukan antara Bhabinkamtibmas dengan Musyawarah nigari (musri) memiliki tujuan yaitu tujuan bersama. Kepala Desa Sikalang, Kota Sawahlunto mengatakan dalam wawancaranya bahwa Hal yang ingin dicapai dari dilakukannya koordinasi antara Bhabinkamtibmas dengan Musyawarah nigari (musri) untuk menciptakan rasa aman bagi seluruh masyarakat, khususnya untuk mengantisipasi agar tindak kejahatan pencurian yang sering terjadi 
di Desa Sikalang, Kota Sawahlunto, dimana menimbulkan keresahan masyarakat ini, tidak terulang lagi.

Berdasarkan hasil wawancara di atas, penulis menyimpulkan bahwa koordinasi yang dilakukan dalam penanganan tindak kejahatan pencurian yang sering terjadi di Desa Sikalang, Sawahlunto dengan tujuan bahwa langkah-langkah yang dilakukan oleh pihak Polsek Sawahlunto bekerja sama dengan pemerintah setempat dapat menciptakan rasa aman bagi seluruh masyarakat dari kejahatan pencurian yang sangat meresahkan, agar tindakan-tindakan kejahatan tersebut tidak terulang lagi.

Koordinasi ini juga dapat mendorong masyarakat untuk bertukar pikiran, sebagaimana di terangkan oleh petugas Bhabinkamtibmas Sawahlunto, bahwa Bhabinkamtibmas sendiri mempunyai inovasi dari Kapolres Sawahlunto dimana setiap hari jumpat pada ibadah jumat, Bhabinkamtibmas di setiam masjid-mesjid menyampaikan pesan-pesan kamtibmas, salah satunya mengenai penanganan pencurian, termasuk juga di setiap sekolah yang ada di Desa Sikalang, Kota Sawahlunto, hal ini dengan alasan karna pelaku kejahatan pencurian itu banyak dari anak-anak sekolah juga.

Berdasarkan hasil wawancara di atas, penulis menyimpulkan bahwa dengan adanya Bhabinkamtibmas di setiap Desa di Sawahlunto, maka berdasarkan tuntutan Bapak Bhabinkamtibmas Sawahlunto dalam hal ini Bhabinkamtibmas pada setiap hari jum'at setelah menunaikan ibadah shalat jum'at akan memberikan penyampaian atau himbauan melalui pesan kamtibnasnya termasuk dalam hal memberikan pemahaman dan meminta kerjasama masyarakat setempat dalam menanggulangi tindak kejahatan pencurian. Penyuluhan juga dilakukan ke sekolah-sekolah pada saat upacara bendera di hari Senin, karena kejahatan pencurian yang marak terjadi di Sawahlunto sebagian besar pelakunya adalah remaja- remaja yang masih dalam tahap pendidikan atau remaja yang menganggur.

Koordinasi ini juga dapat mendorong masyarakat untuk berpartisipasi dalam menanggulangi kejahatan pencurian di Desa Sikalang, Kota Sawahlunto. Dalam wawancara yang dilakukan kepada tokoh masyarakat, bahwa koordinasi yaitu sosialisasi yang dilakukan pada kelurahan oleh bhabinkamtibmas dan Musyawarah Nagari (musri), serta masyarakat. Kemudian disampaikan bahwa ada kegiatan-kegiatan atau di masjid-mesjid sewahtu habis shalat jumat. Akan tetapi kegiatan ini juga kadang tidak terlaksana, karna kegiatan ini juga tergantung pada kesadaran dari si pencuri, dimana pencuri ini melakukan pencurian dipengaruhi oleh lingkungan, karena kurangnya pengawasan dari orang tua terhadap sikap anak-anaknya. Sehingga berdampak pada tidak terkontrolnya diri anak-anak dan berdapak pada perlakuannya yang semaunya anak tersebut dalam melakukan segala hal. Dimana, rata-rata pencurian dilakukan oleh nak-anak yang masih sekolah dimana anak-anak ini masih dalam masa labil.

Berdasarkan hasil wawancara di atas, penulis menyimpulkan bahwa koordinasi penaggulangan kejahatan pencurian dilakukan melalui sosialisasi dengan melibatkan pihak kepolisian, pemerintah setempat, dan masyarakat yang di lakukan di Sawahlunto, begitu pun dalam berbagai kegiatan sosial tetapi belum maksimal. Kemudian masalah pencurian yang masih saja sering terjadi di Sawahlunto, dikarenakan kurangnya perhatian orang tua dalam mengawasi 
anak-anaknya, padahal yang terlibat dalam kejahatan pencurian rata-rata anak sekolah yang masih labil sehingga anak-anak mudah terpengaruh oleh lingkungan pergaulan.

Koordinasi yang dilakukan antara Bhabinkamtibmas dengan Musyawarah nagari (musri) ini, juga dapat membina human relations yang baik, berdasarkan wawancara yang dilakukan dengan Kepala Desa Sikalang, Kota Sawahlunto menjelaskan bahwa, Terdapatnya koordinasi antara Musyawarah nagari dengan Bhabinkabtimnas di Desa Sikalang, Kota Sawahlunto, koordinasi ini dilakukan di setiap Kelurahan yang ada di Desa Sikalang, Koata Sawahlunto. Sehingga hal ini dapat mengontrol tindakan-tindakan di setiap wilayah, kemudian pemerintah setempat bekerjasama dengan aparat kepolisian melakukan sosialisasi, dengan mengundang kepala desa serta masyarakat guna menyampaikan dan meminta informasi-informasi dan masukan dari masyaraka Desa Sikalang, Kota Sawahlunto.

Berdasarkan wawancara di atas, penulis menyimpulkan bahwa Polsek Sawahlunto melakukan koordinasi dengan pemerintah setempat, maupun masyarakat dalam menanggulangi tindak kejahatan pencurian di Sawahlunto dengan melakukan sosialisasi untuk menyampaikan dan mengumpulkan informasi-informasi tentang adanya pencurian di beberapa tempat. Koordinasi yang dilakukan antara Bhabinkamtibmas dengan Musyawarah nagari (musri) dilakukan dengan komunikasi informal. Bapak Kapolres Sawahlunto menerangkan dalam wawancaranya bahwa Koordinasi antara Bhabinkamtibmas dengan Musyawarah Nagari (musri) sudah dilakukan selama ini, yang dilaksanakan di setiap kelurahan, dimana di setiap kelurahan di tempatkan satu Bhabinkamtibmas. Kemudian setelah dilakukannya koordinasi antara Bhabinkamtibmas dengan Musyawarah Nagari (musri) kemudian menyiapkan satu forum untuk dihadiri oleh Kapolsek atau Wakapolsek Sawahlunto. Kemudian Kapolsek dan Wakapolsek mendatangi kelurahan tersebut untuk kemudian dikumpulkan masyarakat dan kemudian diberikan sosialisasi mengenai pencurian.

Berdasarkan hasil wawancara di atas, penulis menyimpulkan bahwa dalam menanggulangi kejahatan pencurian di Sawahlunto, Polsek Sawahlunto melakukan koordinasi dengan pemerintah setempat dengan menempatkan Bhabinkamtibmas (Bintara pembina keamanan dan ketertiban) di setiap Kelurahan untuk melakukan pembinaan keamanan dan ketertiban dengan perangkat desa/kelurahan seperti Kepala Kelurahan, Kepala Lingkungan, atau tokoh-tokoh masyarakat yang dianggap sebagai petua di wilayah Sawahlunto. Bentuk koordinasi yang dilakukan dalam penanganan tindak kejahatan pencurian, dimana Bhabinkamtibmas dan Lurah menyiapkan satu forum untuk melakukan sosialisasi yang dihadiri oleh Bapak Kapolsek dan Wakapolsek dan masyarakat di Sawahlunto.

Berdasarkan hasil wawancara mengenai koordinasi vertikal dalam penanggulangan kejahatan pencurian di Sawahlunto, penulis dapat menyimpulkan bahwa bentuk koordinasi antara Polsek Sawahlunto dengan pemerintah dan masyarakat dalam penanggulangan tindak kejahatan pencurian di Sawahlunto, dimana Polsek Sawahlunto melakukan koordinasi dengan menempatkan Bhabinkamtibmas di setiap Kelurahan selaku pengontrol dan pembina keamanan dan ketertiban masyarakat melalui sosialisasi dengan melibatkan pemerintah yaitu Lurah serta masyarakat setempat. 
Selain koordinasi vertical, juga terdapat koordinasi Horizontal. Koordinasi Horisontal adalah mengkoordinasikan tindakan-tindakan atau kegiatan-kegiatan penyatuan, pengarahan yang dilakukan terhadap kegiatan-kegiatan penyatuan dalam tingkat organisasi (aparat) yang setingkat. Koordinasi horizontal ini relatif sulit dilakukan, karena koordinator tidak dapat memberikan sanksi kepada pejabat yang sulit. Koordinasi horizontal merupakan koordinasi tindakan-tindakan atau kegiatan-kegiatan penyatuan, pengarahan yang dilakukan oleh Kapolres Sawahlunto terhadap anggota kepolisian lainnya sebagai kesatuan kerja dalam menanggulangi kejahatan pencurian di Sawahlunto.

Kendala Dalam Pemberdayaan Kerjasama Musyawarah Nagari (Musri) Di Kota Sawahlunto Dengan Bhabinkamtibmas Polres Sawahlunto Dalam Penanggulangan Kejahatan

Kendala yang dihadapi yaitu, Dalam penyelesaian tindak pidana ringan yang dilakukan oleh Bhabinkamtibmas, ada beberapa petugas Bhabinkamtibmas yang belum memahami secara keseluruhan tentang teknik penyelesaian masalah yang dihadapinya seperti cara pembuatan laporan dan pengarsipan yang sesuai dengan petunjuk yang ada sehingga rekapitulasi laporan masalah yang telah diselesaikan oleh petugas Bhabinkamtibmas belum maksimal dan cara pengarsipan data juga belum tertata rapi.

Masyarakat dan kejahatan tidak dapat dipisahkan. Kejahatan sebagai suatu hasil interaksi antara kepentingan individu di satu pihak maupun kelompok mengakibatkan terciptanya masyarakat kelas bawah dan kelas atas dan semua ini bermuara pada kecemburuan sosial. Ada kesan di masyarakat sekarang bahwa kejahatan dilakukan oleh orang-orang yang tidak berpenghasilan atau penghasilan rendah. Pemahaman ini hampir melekat pada setiap petugas maupun aparat Penegak Hukum. Padahal sebenarnya kejahatan itu banyak dilakukan oleh individu yang secara ekonomis, segi pendidikan dikategorikan mampu. Kenyataan ini semakin menggejala dan sulit dicegah. Pencegahan Kejahatan Pencegahan merupakan kebijakan yang cukup dapat dipertanggung jawabkan terhadap bahaya ancaman tingginya tingkat kejahatan.

Berbagai pemikiran dan pendapat yang berkembang baik pada kalangan akademisi maupun praktisi selalu menghendaki kebijakan pencegahan kejahatan melalui pendekatan kemasyarakatan, hal ini dapat kita lihat di Indonesia seperti adanya siskamling (Sistem Keamanan Lingkungan). Bentuk ini dianggap lebih praktis dan tidak memerlukan sarana yang banyak. Masalahnya adalah perlu ada kejelasan di masyarakat untuk konsisten mempertahankan pola tersebut. Pencegahan kejahatan itu sendiri dapat diusahakan melalui beberapa hal, seperti mempersiapkan petugas profesional di setiap wilayah (pemukiman/tempat tinggal) masyarakat secara efektif dan efisien. Memberikan penerangan disekitar wilayah rawan ancaman kejahatan. Membentuk kelompok-kelompok dalam masyarakat untuk mengorganisasikan kegiatankegiatan sosial yang berdampak terhadap keamanan lingkungan. Menghargai prestasi-prestasi warga masyarakat yang mempunyai minat terhadap lingkungan. 


\section{KESIMPULAN}

Dilakukan sosialisasi hukum yang lebih intensif terhadap masyarakat sehingga dapat memahami setiap proses hukum dengan baik. Peningkatan kapasitas kemampuan petugas Bhabinkamtibmas sehingga dapat memahami secara keseluruhan tentang teknik penyelesaian masalah yang dihadapinya.

\section{DAFTAR PUSTAKA}

Gunawan, Kian. (2008). Hukum Agraria Indonesia: Himpunan Peraturan Hukum Tanah. Yogyakarta: Pustaka Grahatama.

Bambang Poernomo, Pola Dasar Teori - Azas Umum Hukum Acara Pidana Penegakan Hukum Pidana, Liberty, Yogyakarta, 1993

Zainuddin Ali, Sosiologi Hukum, Sinar Grafika, Jakarta, 2009

Robert O’Block L, Security and Crime Preventio, Mosby Company, St Louis, 1981

Robert J. Fischer and Gion Green, Introduction to Security. Elsevier Science USA, Butterworth Heinemann, sixth Ed,1998

Sadjijono, Memahami Hukum Kepolisian, Laksbang PRESSindo, Yogyakarta, 2010

Satjipto Raharjo, Mengkaji Kembali Peran dan Fungsi Polri Dalam Era Reformasi. Makalah Seminar Nasional. Jakarta, 2003

Buku Pintar BHABINKAMTIBMAS, 2014 